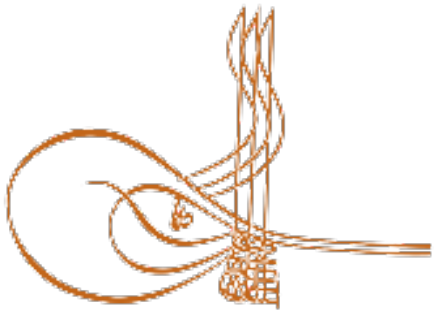

www.turkishstudies.net/language
Turkish Studies - Language and Literature

eISSN: $2667-5641$

Research Article / Araştırma Makalesi

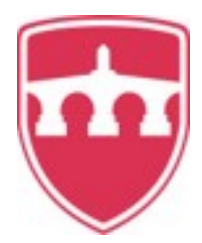

INTERNATIONAL

BALKAN

UNIVERSITY

Sponsored by IBU

\title{
Dîvânü Lügâti’t-Türk’te Sayı Sistemi ve Sayı Adları
}

Number System and Number Names in Dîvânü Lügâti't-Türk

Ömer Çakmakcı ${ }^{*}$

\begin{abstract}
Dîvânü Lügâti't-Türk which was written between the years 1074-1077 by Kâş̧garlı Mahmud ise one of the main works of the 11th-century. The work was written in order to teach Turkish to Arabs. For this reason, beginning items were arranged in the form of dictionary from Turkish to Arabic and given examples in order to be understood the meaning of words very well. This dictionary is accepted one of the works of Islamic period with Kutadgu Bilig which was written in the period of Karahans. The content of the work is very rich and this language material was collected from the Turkish world. It contains about 8000 words. In this study, the numbers matter and the system that the numbers created will be discussedThe dictionary which gives the various informations about the names of people, tribes and places; Turkish geography and folk literature is an encyclopedic work. As in all matters, Dîvânü Lügâti't-Türk gives informations about the numarel names which have an important place in the lexicon of languages and accepted as the basic words by linguists. Usually in languages there are cardinal numbers and drived numbers which are maden because of needing. In this study was explained the system of Turkish numbers, number names, cardinal numbers and ordinal numbers in Dîvânü Lügâti't-Türk. Turkish numbers have been classified under there main headings such as cardinal numbers, drived numbers and ordinal numbers. Firstly, the numbers in the classificattions were mentioned as beginning items and given examples about the numbers in the texts. Later, was shown the method of ordinal number derivation in Turkish. At the same time, in this study it is aimed to reveal that from the ancient times to the present day, decimal sytem was the dominant one between Turkish people.
\end{abstract}

Structured Abstract: The treatise named Dîvânü Lügâti't-Türk which is written by Kaşgarlı Mahmud is the first known Turkish dictionary. The source of this treatise is Turkic World and it is an important work in term of vocabulary. Because of the context which contains person, tribe and place names and also excessive subjects about Turkish history, geography and folk literature, the treatise gains an encyclopedical value. Some other points like giving specialties of language in 11th century, indicating phonetic and morphological details and also having comparative knowledge of various Turkic tribes' dialects increase its importance. In this treatise, Kaşgarlı Mahmud also gives place to the dialects of Oghuzs, Kıpchaks, Argus and other tribe's dialects as well as using the standart language of his period. That's why he called his treatise Türk lügâtı (Turkic languages) instead of Türk lügatı (Turkic Language). Since it is a work for teaching Turkish language to Arabs, it has been

\footnotetext{
*Yüksek Lisans Öğrencisi, Kocaeli Üniversitesi, Fen-Edebiyat Fakültesi, Türk Dili ve Edebiyatı Master Student, Kocaeli University, Faculty of Science and Literature, Turkish Language and Literature ORCID 0000-0003-1789-3223 omercakmakci25@hotmail.com

Cite as/ Atıf: Çakmakcı, Ö. (2020). Dîvânü Lügâti't-Türk’te sayı sistemi ve sayı adları, Turkish Studies - Language, 15(1), 79-86. https://dx.doi.org/10.29228/TurkishStudies.40181

Received/Geliş: 16 December/Aralık 2019

Accepted/Kabul: 24 March/Mart 2020

Copyright à INTAC LTD, Turkey
} 
arranged as from Turkish to Arabic and its introduction and commantaries is written in Arabic. One of the other points that makes this treatise important that; the words placed as lexical entry and also the explanations of the words contains proverbs, idioms, poetries to support the meaning.

The only hand-written copy of this treatise is found by Ali Emiri Efendi in a second-hand book seller in 1917 and brought in to social studies world. After that, with approval of Ali Emiri Efendi, examination and adjustments of Kilisli Rifat Bilge, it was published with Arabic letters. After the publication, M. Fuad Köprülü, Necip Asım, Besim Atalay, Ahmet Caferoğlu and C. Brockelmann being in the first place, there was a great deal of other examinations. In the first place there was an unpublished translation to Turkish by Kilisli Rifat Bilge, Abdullah Atıf Tüzüner and Abdullah Sabri. Later, an indexed translation of three volume by Besim Atalay was published. Afterwards, it was translated to New Uigur, Uzbek and English languages. One of the newest publication was in 2015, by Ahmet Bican Ercilasun and Ziya Akkoyunlu with the name Dîvânü Lügati't Türk.

In Dîvânü Lügâti't-Türk, there is also informations about numeral systems of different periods. Since the numeral systems is important for periods of Turkish language history and also indicating them as entries in some parts, makes the work more important. Aforementioned work also refers to etymology about depicted numbers. The improvements of numeral system differs in all World languages. But typically there is cardinal numbers and numbers created according to needs. Cardinal numbers shape in ancient times and would not change to a large extent. These cardinal numbers virtually language mementos which has primitive character. New words, since they are created in needs, would ring the changes from time to time. These numbers, in general, are secondary numbers which appears according to needs in the form of derivation. They are not as old as cardinal numbers. Also Ordinal numbers, formation method of ordinal number are depicted under the entry. A similar usage also can be seen in Eski Uygur Türkçesi Sözlüğü ve An Etymological Dictionary of Pre-Thirteenth Century Turkish too.

In Turkish language, the main numeral system is decimal system. It is possible to see it in the examples as seksen ( $<$ sekiz on) or doksan $(<$ dokuz on). In this treatise, there is various of detailed examples about this subject. This case also have been explained in the other examined dictionary in particular. Tokuz on: doksan (EDPT: 473); sekiz on: seksen (EUTS: 199).

The material of vocabulary that is acquired from the aforementioned text is classified under three major topics: Cardinal numbers, secondary numbers and ordinal numbers. Besides it is seperated considiring the number is on the entry or in the text. This study is based on the publication of Ahmet Bican Ercilasun and Ziya Akkoyunlu. On the other hand, if the given words is placed as entry, it is given as comparative with Sir Gerhard Causon's work An Etymological Dictionary of Pre-Thirteenth Century Turkish and Ahmet Caferoğlu's Eski Uygur Türkçesi Sözlüğ̈̈. The reason for this is to verify the progress of advancement of the names of numbers. Even if the number was not given on the entry, still it is studied in a comparative way of the mentioned treatises as in its form in the text.

DLT mentions about both cardinal and secondary numbers. Cardinal numbers do not indicate much differences of ET, apart from some phonetic dissimilarities. However; numbers like "yigirmi, ottuz" are accepted as artifical numbers in World languages. But in Turkic numbers this case slightly divergent. Since there is not any sign of compounding or fixing, in Turkish, the numbers, except seksen and doksan, have the character of cardinal numbers. Kaşgarlı Mahmud explained how these numbers compounded as an entry.

Same as in the periods of Turkish history, in this treatise also there is decimal system. It is an ancient system that have been applied in military by Metahan. So it is possible to base upon this numeral system to him. At the same time it is seen that adding + nç suffix is used for forming ordinal number. Kaşgarlı Mahmud explains how it is formed and it is regular or not in his work. Also +nt suffix which is the ordinal numeric expression in Old Turkic, is not referred as a ordinal number function but as ordinal numeral adjective. İkindi, ikindi nèy: second one of the numbers. (Ercilasun-Akkoyunlu, 2015: 72); ekindi: ikinci (EDPT: 111); ikindi äkinti ikinti: ikinci (EUTS: 91).

It is confirmed in this study that, there is not much differences with the name of the numbers between the treatise and present day. For example; the number which is used as iki in present day, mentioned in the work as ikki $\sim \mathrm{iki}$. As it can be seen in the treatise, more of the cardinal numbers took place and for the most parts, these numbers placed predominantly as an entry. 
Keywords: Karakhan Turkish, Dîvânü Lügâti’t-Türk, Number Names, Number System, Cardinal Number, Ordinal Number.

Öz: Kâşgarlı Mahmud'un 1074-1077 yılları arasında kaleme aldığı Dîvânü Lügâti't-Türk, 11. asrın temel eserlerindendir. Eser, Araplar'a Türkçe'yi öğretmek maksadıyla yazılmıştır. Bu sebeple madde başları Türkçe'den Arapça'ya bir lügat şeklinde tanzim edilmiş, kelime manalarının daha iyi anlaşılması için misaller verilmiştir. Bu lügat, Karahanlılar zamanında yazılan Kutadgu Bilig ile beraber ilk İslamî devir eserlerinden kabul edilir. Eserin muhtevası son derece zengindir ve bu dil malzemesi Türk dünyasından derlenmiştir. Yaklaşık olarak 8000 kelime ihtiva eder. Bu çalışmada ise eserdeki sayılar bahsi ve bu sayıların meydana getirdiği sistmem ele alınacaktır. Şahıs, kabile, yer adları; Türk coğrafyası ve halk edebiyatına dair çeşitli bilgiler veren lügat, ansiklopedik mahiyette temel bir eserdir. Dîvânü Lügâti't-Türk, birçok mevzuda olduğu gibi söz varlı̆̆ında ehemmiyetli bir yer tutan ve lisaniyat alimleri tarafından temel kelimler arasında kabul edilen sayı adları hakkında malumat vermektedir. Dillerde, umumiyetle asıl sayılar ve sonradan ihtiyaç halinde yapılmış olan türetme sayılar yer vardır. Bu çalışmada, Dîvânü Lügâti’t-Türk’teki Türkçe sayı sistemi, sayı adları üzerinde durulmuştur. Türkçe sayılar; asıl sayılar, türetme sayılar ve sıra sayıları olmak üzere üç ana başlık altında tasnif edilmiştir. Evvela tasnifteki sayılar madde başı olarak zikredilmiş, sayılarla alakalı metin içinde örnek cümleler verilmiştir. Daha sonra Türkçe sıra sayı yapma metodu gösterilmiştir. Aynı zamanda bu çalışmada Türklerde kadim yıllardan günümüze gelen onluk sistemin de hakim anlayış olduğu ortaya konulması amaçlanmıştır.

Anahtar Kelimeler: Karahanlı Türkçesi, Dîvânü Lügâti’t-Türk, Sayı Adları, Sayı Sistemi, Asıl Sayı, Sıra Say1.

\section{Giriş}

Kâşgarlı Mahmud'un kaleme almış olduğu Dîvânü Lügâti't-Türk adlı eser, Türkçe'nin bilinen ilk lügatidir. Eserin malzemesi Türk dünyasından toplanmıştır. Türk dilinin söz varlığı bakımından mühim bir kaynaktır. Şahıs, kabile ve yer adları ile beraber Türk tarihine, coğrafyasına ve halk edebiyatına dair birçok mevzuyu ele alması, esere ansiklopedik bir mahiyet kazandırmıştır. Türkçe'nin ilk lügati olmasının yanı sıra Türk dilinin 11. asırdaki belli başlı dil hususiyetlerini, ses ve şekil bilgisini göstermesi; çeşitli Türk boylarının ağızları üzerinde mukayeseli malumat vermesi; ekseriyetle Karahanlı Türkçesi üzerinde dursa da bilhassa Oğuz Türkçesi ile alakalı bilgiler ihtiva etmesi eserin ehemmiyetini arttıran noktalardır. Kâşgarlı Mahmud, bu eserinde devrinin standart dilinin lügatini yazmakla beraber Oğuzlar, Kıpçaklar, Argular gibi muhtelif Türk boylarının ağızlarına da yer vermiştir. Bu yüzden eserine "Türk lügati (Türk dili)" yerine "Türk lügâti (Türk dilleri)" demiştir. Eser, Araplar’a Türkçe öğretmek maksadıyla yazıldığı için Türkçe'den Arapça'ya bir lügat şeklinde tanzim edilmiş, eserin mukaddimesi ve açıklama kısımları Arapça olarak kaleme alınmıştır. Bu eseri ehemmiyetli kılan hususlardan biri de, kelimelerin madde başı olarak yer alması ve kelimelerin izahatı yapılırken manalarının daha iyi anlaşılması için halk deyişleri, atasözleri ve şiirlerinden misaller verilmesidir.

Tek yazma nüshası olan bu eser, 1917 senesinde İstanbul Beyazıt Camii yanındaki bir sahafta Ali Emiri Efendi tarafından bulunup ilim dünyasına kazandırılmıştır. Daha sonra Ali Emiri'nin de tasdiki ile eser Kilisli Rifat Bilge tarafından tetkik ve tashih edilerek Arap harfleri ile neşredilmiştir. Bu neşriyattan sonra eserle alakalı olarak M. Fuad Köprülü, Necip Asım, Besim Atalay, Ahmet Caferoğlu ve C. Brockelmann başta olmak üzere yurt içi ve yurt dışında birçok ilmî tedkikat yapılmıştır. Eser ilk başta Kilisli Rifat Bilge, Abdullah Atıf Tüzüner ve Abdullah Sabri Karter tarafindan Türkçe'ye tercüme edilmiş ancak neşredilmemiştir. Daha sonra Besim Atalay'ın yaptığı tercüme üç cilt halinde ve bir indeks ilavesi ile neşredilmiştir. Eser bilahare Yeni Uygurca'ya, Özbekçe ve İngilizce'ye de tercüme edilmiştir. Günümüze yakın en yeni neşirlerden birini de 2015 
yılında Ahmet Bican Ercilasun ve Ziyat Akkoyunlu Dîvânü Lügati’t Türk adıyla yapmıştır. Bu çalışmada da bu neşriyat esas alınmıştır.

Dîvânü Lügâti’t-Türk’te Türk dilinin çeşitli devirlerindeki sayı sistemleri hakkında da bilgi verilmiştir. Sayı sisteminin hem Türk dilinin tarihi devreleri bakımından ehemmiyet arz etmesi hem de eserde yer yer madde başı olarak gösterilip metin içinde zikredilmesi, eserin kıymetini arttıran hususlardır. Bahsi geçen eserde, tarif edilen sayılar hakkında zaman zaman etimolojiye de temas edilmiştir.

Sayı sisteminin gelişimi dünya dillerinde farklılık arz etmektedir. Dillerde umumiyetle asıl sayılar ve sonradan ihtiyaç halinde yapılmış olan yeni sayılar vardır. Asıl sayılar, çok eski devrelerde ortaya çıkarlar ve büyük ölçüde değişikliğe uğramazlar. Yeni sayılar ise daha sonradan ortaya çıktığı için zaman zaman değişikliğe uğrayabilirler.

Türk dilinde sayılarda onluk sistem hakimiyeti esastır. Bunu, seksen $(<$ sekiz on) yahut doksan ( $<$ dokuz on) misallerinde görmek mümkündür. Bunun tafsilatlı örnekleri bu çalışmada görülebilir. Bu durum, incelenen lügatlerde de hususi olarak izah edilmiştir. Tokuz on: doksan (EDPT: 473); sekiz on: seksen (EUTS: 199).

\section{2. İnceleme Metodu}

Alakalı metnimizden elde edilen söz varlığına dair malzeme asıl sayılar, türetme sayılar, sıra sayılar olmak üzere üç ana başlık altında tasnif edilmiştir. Ayrıca bu sayıların madde başında mı yoksa metin içinde mi yer aldığına dikkat edilmiş, buna göre de bir ayrıma gidilmiş̧tir. Bu çalışmada Ahmet Bican Ercilasun ve Ziyat Akkoyunlu'nun neşri esas alınmıştır. Diğer taraftan verilen bu kelimeler, eğer madde başı olarak yer almışsa yanında Sir Gerhard Clauson'un 13. asır öncesi Türkçe söz varlığına dair An Etymological Dictionary of Pre-Thirteenth Century Turkish adlı çalışması ve Ahmet Caferoğlu'nun Eski Uygur Türkçesi Sözlüğü ile de mukayese edilerek verilmiştir. Bundaki maksat ise sayı adlarının gelişim seyrini tarih süreç içerisinde tahkik etmektir. Sayı; madde başı olarak verilmemişse, metin içinde geçen kısımda yine bu eserlerde geçen formuyla mukayese etme yoluna gidilmiştir.

\section{Söz Varlığı Araştırması}

\subsection{Asıl Sayılar}

Bu sayılar, dillerde çok eski devirde ortaya çıkmış sayılardır. İptidai nitelik gösteren en eski dil yadigarlarındandır.

\subsubsection{Madde Başı}

3.1.1.1. bir: sayıda bir. bír yarmak: bir dirhem. Bír şekliyle ortada illet harfi bulunan bâba da sokulabilir. Bunun benzer misalleri çoktur. Fakat Türk lehçelerinde en doğrusu ve en fasihi, lafzen kısa ve mahreç bakımından sert olanlarıdır (Ercilasun-Akkoyunlu, 2015: 14); bir bír: bir (EDPT: 353); bir: bir (EUTS: 43). bír: bir. Bír yarmak: bir dirhem (Ercilasun-Akkoyunlu, 2015: 397)

3.1.1.2. ikki: sayılardan iki (Ercilasun-Akkoyunlu, 2015: 66); èkki: iki (EDPT: 100); iki: iki (EUTS: 91).

3.1.1.3. üç: sayıda üç. Üç dirhem anlamında üç yarmak denir (Ercilasun-Akkoyunlu, 2015: 16); üç: üç (EDPT: 18); üç: üç (EUTS: 270).

3.1.1.4. tört: dört. Tört yarmak: dört dirhem dört olan her şey için tőrt. Doğrusu vav ile tört’tür (Ercilasun-Akkoyunlu, 2015: 148); tört (?dörd): tört (EDPT: 534); tört: dört (EUTS: 249).

3.1.1.5. bíş̧: sayıda beş (Ercilasun-Akkoyunlu, 2015: 399); besş: beş (EDPT: 376); biş: beş (EUTS: 45). 
3.1.1.6. yetti: sayılardan yedi. Yetti kat kök: yedi kat gök (Ercilasun-Akkoyunlu, 2015: 359); yetti: yedi (EDPT: 886); yiti: yedi (EUTS: 299).

3.1.1.7. sekiz: sayıda sekiz. Sekizin hafifletilmiş şeklidir (Ercilasun-Akkoyunlu, 2015: 157); sekkiz: sekiz (EDPT: 823); säkiz: sekiz (EUTS: 199).

3.1.1.8. on: sayıda on (Ercilasun-Akkoyunlu, 2015: 23); ōn: on (EDPT: 166); on: on (EUTS: 141).

3.1.1.9. min: sayılarda bin (Ercilasun-Akkoyunlu, 2015, 493); bin: bin (EDPT: 346); min: bin (EUTS: 130).

3.1.1.10. milyon: sayıda milyon. Tümen min yarmak: bir milyon dirhem (ErcilasunAkkoyunlu, 2015: 173).

\subsubsection{Metin İçi}

3.1.2.1 bír bıçım kāgun: bir dilim kavun (Ercilasun-Akkoyunlu, 2015: 6); bír adut nèng: bir avuç şey (Ercilasun-Akkoyunlu, 2015: 24); bír öpüm mün: bir yudum çorba (Ercilasun-Akkoyunlu, 2015: 35); bir kes ekmek: bir parça ekmek (Ercilasun-Akkoyunlu, 2015: 143); bír tilim et: bir dilim et (Ercilasun-Akkoyunlu, 2015: 171); bír tilge et: bir parça et (Ercilasun-Akkoyunlu, 2015: 186); bír nèn bírke karıldı: bir şey bir şeye karıştı (Ercilasun-Akkoyunlu, 2015: 271); ol bír nėnni bírke tengerdi: bir şey bir şeyle denkleşti (Ercilasun-Akkoyunlu, 2015: 271); begler bír ikindi bir agışdı: beyler birbirleriyle itiştiler (Ercilasun-Akkoyunlu, 2015: 94); olar bír bírke bitig ötrüşdi: ikisi birbirine mektup vb. şeyler ulaştırdılar (Ercilasun-Akkoyunlu, 2015: 109); olar bír ekindidin ketişdi: o ikisi birbirinden ayrıldı (Ercilasun-Akkoyunlu, 2015: 257).

3.1.2.2. iki beg birle íl boldı: iki hakan arasında barış oldu (Ercilasun-Akkoyunlu, 2015: 23); íki nėn koşlundı: iki şey birbirine koşuldu (Ercilasun-Akkoyunlu, 2015: 307); bír tilkü terisin iki la soymas: bir tilkinin derisi iki defa soyulmas (Ercilasun-Akkoyunlu, 2015: 455); ikki yag ugraşdı: iki düşman birbirinin üzerine yürüdü (Ercilasun-Akkoyunlu, 2015: 110) ikki kaz üçlendi: iki kaz vb. üçleşti (Ercilasun-Akkoyunlu, 2015: 116); ol ikki kişi otra araladı: o iki adamı barıştırdı (ErcilasunAkkoyunlu, 2015: 135); ikki begler karıştılar: iki bey ihtilafa düşüp dövüştüler (ErcilasunAkkoyunlu, 2015: 260); olar ikki bír bírig suwka batruşdı: onlardan her biri bir diğerini suya batırdı (Ercilasun-Akkoyunlu, 2015: 291); olar ikki yaraşdı: o ikisi bir işte uyum sağladı (ErcilasunAkkoyunlu, 2015: 379); olar ikki bír bírke at yetrüşti: o, iki at vb. şeyleri ulaştırmada birbirlerine yardım ettiler (Ercilasun-Akkoyunlu, 2015: 389); olar ikki konuklaşdı: o ikisinden her biri diğerini misafir etti (Ercilasun-Akkoyunlu, 2015: 308).

3.1.2.3. er sözi bír eder köki üç. Anlamı; Erkekliğin gereği olarak onun sözü bir olmalıdır; bundan dönüş olmaz; nasıl ki eyer kaburgasının bağı üçtür; bir tane fazla olursa deliklerin çokluğundan eyer kaşı kırılır; üçten az olursa, iki (bağ) insanı taşımaya dayanamaz. Bu, dediğini yerine getirmek için söylenir. (Ercilasun-Akkoyunlu, 2014: 318).

3.1.2.4 aslı dört anlam: tört (Ercilasun-Akkoyunlu, 2015: 532); aslı dört anlamında tört (Ercilasun-Akkoyunlu, 2015: 66).

3.1.2.5. bíş enek tüz ermes: Anlamı şudur; beş parmak eşit değildir (Ercilasun-Akkoyunlu, 2015: 60); beş anlamında bíş (Ercilasun-Akkoyunlu, 2015: 532)

3.1.2.6. tokuz tūglug xān: dokuz sancağı olan hükümdar ve hakan (Ercilasun-Akkoyunlu, 2015: 400); tokuz: dokuz (EDPT: 474); tokūz: dokuz (EUTS: 245).

3.1.2.7. sū ōn kūn örüg boldı: askerler on gün bir yerde kalıp oradan ayrılmadılar ve gazâ yapmadılar (Ercilasun-Akkoyunlu, 2015: 33); ōn yarmak üze bír arturdı on dirhem üzerine bir artırdı (Ercilasun-Akkoyunlu, 2015: 105). 

2015: 38)

3.1.2.8. yūz at menin agdın keçti: bacaklarımın arasından üç at geçti (Ercilasun-Akkoyunlu,

3.1.2.9. koldakçıka min yagak: dilenciye benden bin ceviz (Ercilasun-Akkoyunlu, 2015: 180)

\subsection{Türetme Sayılar}

Bu sayılar genellikle dillerde ihtiyaç halinde türetme şeklinde zuhur eden ara sayılardır. Asıl sayılar kadar eski değildirler.

\subsubsection{Madde Başı}

3.2.1.1. yigirme: yirmi. Yigirmi biçimi de vardır (Ercilasun-Akkoyunlu, 2015: 369); yėgirmi: yirmi (EDPT: 915); yigirmi: yirmi (EUTS: 296).

3.2.1.2. ottuz yarmak: otuz dirhem veya herhangi bir şey (Ercilasun-Akkoyunlu, 2015: 73); ottuz(ottoz): otuz (EDPT: 74); otuz: otuz (EUTS: 144).

3.2.1.3. ellig yarmak: elli dirhem veya herhangi bir şey (Ercilasun-Akkoyunlu, 2015: 73); ellig (EDPT: 141) ällig: elli (EUTS: 71).

3.2.1.4. seksön: sayllardan seksen. Aslı sekiz ōn'dur; sekiz kere on demektir. İkisi birleştirilmiştir (Ercilasun-Akkoyunlu, 2015: 189); seksőn: seksen (EDPT: 823) säkizon: seksen (EUTS: 199).

3.2.1.5. tokson: sayılardan doksan. Aslı tokuz ōn'dur; dokuz kere on anlamındadır. İkisi birleştirilmiştir (Ercilasun-Akkoyunlu, 2015: 189); tokson: doksan (EDPT: 473).

\subsubsection{Metin İçi}

3.2.2.1. Ergenke ellig karı bözün ūm tükemes: Bekar adamın şalvarı için elli arşın kumaş yetmez. Çünkü ona yabanc1 ögüt vermez. Evlenmesi için istenen kişiye söylenir (ErcilasunAkkoyunlu, 2015: 57).

\subsection{Sira Sayılar}

Sira sayı yapımı metodu madde altında tarif edilmektedir. Buna benzer kullanımı arz edilen Eski Uygur Türkçesi Sözlüğü ve An Etymological Dictionary of Pre-Thirteenth Century Turkish'de görmek mümkündür.

üçünç: sayılardan üçüncü. İkinç: ikinci. Bu kuraldır. On'dan az olan sayılarda, önceki sayıyı takip ettiğini göstermek üzere, kelimenin aslına nun ile cim eklenir. "Dördüncü” anlamında törtünç, "beşinci" anlamında bíşinç denir; asılları, "dörtt" anlamında tőrt ve "beş" anlamında bíş’tir. Bu anlam için nun ve cim eklenmiştir. Köklerde de böyle yapılması caizdir. "Onuncu" için ōnunç, "yirminci" için yigirminç denir. Anlamı "on dokuzdan sonraki"dir. Bu oturmuş bir kuraldır. (ErcilasunAkkoyunlu, 2015: 66); üçünç: sayılardan üçüncü. Bu bir kuraldır. "On"dan az olan sayının köküne, kendinden önceki sayıdan sonra gelmesi istenirse, nun ve cim $(+n c ̧)$ eklenir. "Dördüncü” için törtünç, "beşinci" için bíşinç denir. Aslı "dört" anlamında tört, "beş" anlamında bíş’tir; bunlara bu anlam için gunneli nun (n) ve cim (ç) eklenmiştir. Köklerde (onlu köklerde) de bunula söylenmesi mümkündür. Örnek: onunç "onuncu"; yigirminç "on dokuzdan sonra gelen yirminci." Bu doğru bir kuraldır. (Ercilasun-Akkoyunlu, 2015: 532); ekkinç: ikinci (EDPT: 110); onunç: onuncu (EDPT: 166); birinci: birinci (EUTS: 44); ikinç: ikinci (EUTS: 91); üçünç: üçüncü (EUTS: 271) törtünç: dördüncü (EUTS: 249); onunç: onuncu (EUTS: 142).

ikindi, ikindi nėy: sayılarda, ikinci olan. (Ercilasun-Akkoyunlu, 2015: 72); ekindi: ikinci (EDPT: 111); ikindi äkinti ikinti (EUTS: 91) 
Yukarıdaki izahta görüldüğü Türkçe'nin çok eski devirlerinde de aynı şekilde ifade edilen sıra sayı sıfatlarının sayma sayılarına +nç ve + nd eklenerek kullanılması düzenli bir kaidedir.

\section{Sonuç}

DLT'de sayı isimleri ile alakalı hem asıl sayılar hem de türetme sayılar yer almaktadır. Asıl sayılar, fonetik değişiklikler haricinde ET'den fazla bir farklılık göstermemektedir. Bununla birlikte "yigirmi, ottuz" gibi sayılar her ne kadar dünya dillerinde yapma sayılar kabul edilse de Türkçe sayılarda bu durum biraz farklıdır. Türkçe'de seksen ve doksan sayıları dışındaki sayılar, asıl sayı hususiyeti göstermektedir. Çünkü diğer sayıların birleşme veya kalıplaşma yoluyla oluştuğuna dair bir işaret yoktur. Kâşgarlı Mahmud bu iki sayıyı madde başı olarak açıklarken nasıl birleştiklerini de izah etmiştir.

Türkçe'nin tarihi devrelerinde olduğu gibi bu eserde de sayı sistemi olarak onluk sistem yer alır. Onluk sistem Türkçe'de Metehan zamanına kadar dayanır. Metehan zamanında askerlikte tatbik edilen onluk sistemini de bu sayı anlayışına dayandırmak mümkündür.

Ayrıca sıra sayı ismi yapılırken sayı ismine + nç getirilerek türetildiği de görülür. Kâşgarlı Mahmud bunu eserinde açılar ve bizzat nasıl yapıldığını ve kaideye uygun olup olmadığını söyler. Ayrıca Eski Türkçe'de +nt olarak yer alan sıra sayı ifadesi, bu eserde sıra sayı fonksiyonunda kullanılmakla beraber eserde sadece ikinci sıra sayı sıfatı için kullanılmıştır. İkindi, ikindi nėy: sayılarda, ikinci olan. (Ercilasun-Akkoyunlu, 2015: 72); ekindi: ikinci (EDPT: 111); ikindi äkinti $\sim$ ikinti: ikinci (EUTS: 91).

Çalışmada, eserdeki ve günümüzdeki sayı isimleri arasında fazla bir fark bulunmadığı, sadece birkaç söyleyiş farkının bulunduğu tespit edilmiştir. İki sayısını ele almak gerekirse günümüzde iki olarak kullanılırken eserde ikki iki şeklinde zikredilmiştir.

Eserde görüldüğü üzere, daha çok asıl sayılara yer verilmiş ve genellikle bu sayılar madde başı olarak büyük nispette zikredilmiştir.

Tablo 1: Dîvânü Lügâti't-Türk'te Sayılar

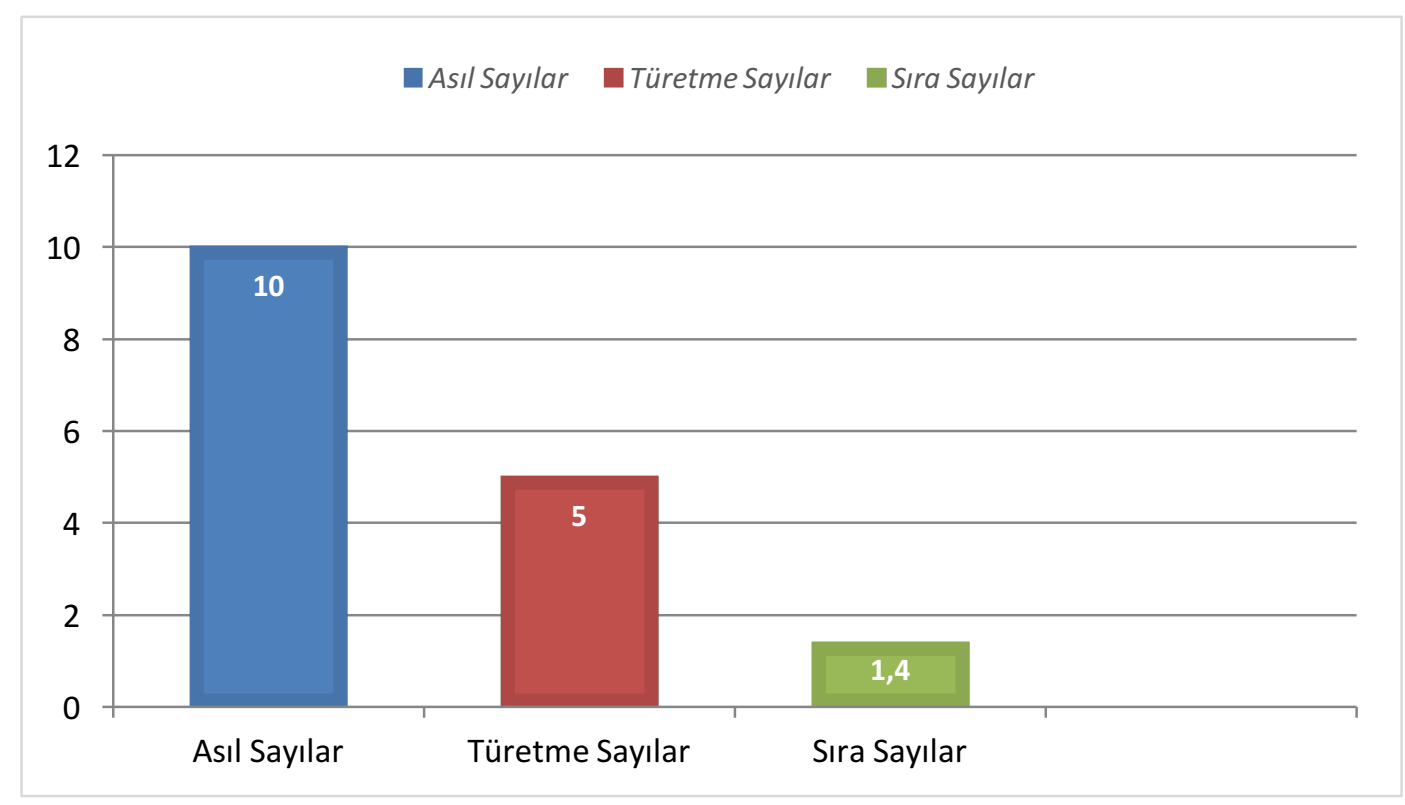




\section{Kaynakça}

Atıcı, A. (2013). "Sungur Türkçesinin Sayı Sistemi Üzerine.” 7. Uluslararası Türk Dili Kurultayı.

Bacanlı, E. (2012). “Geçmişten Günümüze Türkçenin Sayıları ve Sayı Sistemi ” Bilim ve Teknik: 7678.

Caferoğlu, A. (1968). Eski Uygur Türkçesi Sözlüğü, Ankara: Türk Dil Kurumu Yayınları. https://doi.org/10.12787/karam1164

Ercilasun, A.B. (2014). Türk Dili Tarihi, Ankara: Akçağ Yayınları. https://doi.org/10.14222/turkiyat776

Grönbech, K. (2011). Türkçenin Yapısı, (Çeviren Mehmet AKALIN), Ankara: Türk Dil Kurumu Yayınları.

Kâşgarlı Mahmud, (2006). Dîvânü Lügâti't-Türk Cilt 1, (Çeviren Besim Atalay), Ankara: Türk Dil Kurumu Yayınları.

Kâşgarlı Mahmud, (2006). Dîvânü Lügâti 't-Türk Cilt 2, (Çeviren Besim Atalay), Ankara: Türk Dil Kurumu Yayınları.

Kâş̧garlı Mahmud, (2006) Dîvânü Lügâti't-Türk Cilt 3, (Çeviren Besim Atalay), Ankara: Türk Dil Kurumu Yayınları.

Kâşgarlı Mahmud, (2006). Dîvânü Lügâti't-Türk Cilt 4, (Çeviren Besim Atalay), Ankara: Türk Dil Kurumu Yayınları.

Kâşgarlı Mahmud, (2006). Dîvânü Lügâti't-Türk, (Hazırlayan Ahmet Bican Ercilasun-Ziyat Akkoyunlu), Ankara: Türk Dil KurumuYayınlar1. https://doi.org/10.7827/turkishstudies.933

Kaymaz, Z. (1997). “Türklerde Sayı Sistemleri.” 9. Milli Türkoloji Kongresi, İstanbul: Türkiyyat Araştırmaları Enstitüsü.

Küçük, S. (2015). Sayı Grubu Yönünden Eski Türkçe ile Karaçay-Balkar Türkçesinin Karşılaştırılması, Ordu: Ordu Üniversitesi. https://doi.org/10.9761/jasss2794

Şarşenbek Uulu, T. (2015). "Manas Destanındaki Bazı Sayı Yapıları ve Sayı İsimleri Üzerine." Uluslararası Türkçe Edebiyat KültürĔgitim Dergisi: $4 . \quad$ 122-137. https://doi.org/10.7884/teke.431

Tekin, T. (2006). Orhon Yazıtları, Ankara: Türk Dili Kurumu Yayınları.

\section{Kisaltmalar}

DLT : Dîvânü Lügâti’t-Türk

EDPT : An Etymogical Dictionary of Pre-Thirteenth Century Turkish

EUTS : Eski Uygur Türkçesi Sözlüğü

ET : Eski Türkçe 